\title{
APLICAÇÃO DO MÉTODO HÍBRIDO AHP-TOPSIS-2N PARA ORDENAÇÃO DA EXECUÇÃO DE FUROS DE ALÍVIO EM REVESTIMENTOS DE POÇOS DE PETRÓLEO SOB RISCO DE COLAPSO
}

\author{
Humberto Magno Barbosa \\ UFF - Universidade Federal Fluminense \\ Avenida Henrique Valadares, 28 - Centro - Rio de Janeiro, RJ - Brasil \\ humbertombh@gmail.com \\ Carlos Francisco Simões Gomes \\ Universidade Federal Fluminense (UFF) \\ cfsg1@bol.com.br \\ Marcos dos Santos \\ Instituto Militar de Engenharia (IME) \\ Praça Gen. Tibúrcio, 80 - Urca, Rio de Janeiro - RJ, 22290-270 marcosdossantos_doutora- \\ do_uff@yahoo.com.br
}

\begin{abstract}
RESUMO
Este trabalho tem como objetivo apresentar uma aplicação prática da ferramenta AHP TOPSIS 2N, como suporte para a tomada de decisão na indústria de petróleo e solução para o problema de ordenação e priorização de uma lista de doze poços injetores de fluidos a sofrerem intervenção para execução de furos de alívio (para redução de pressão interna dos revestimentos). Poços injetores de fluidos são usados para manter a pressão interna do reservatório de petróleo e com isto garantir maior fator de recuperação de óleo e gás natural do reservatório. Quatro critérios foram selecionados por especialistas como sendo os mais relevantes para a construção da matriz de decisão: perda de produção, tempo de vida útil do poço até colapso, tempo até troca de linha de injeção devido fenômeno de SCC $\mathrm{CO}_{2}$ e tipo de fluido contido nos espaços anulares entre revestimentos de poço. Com os dados coletados através de metodologia simplificada, foi executado o programa AHP TOPSIS 2N, que é considerado um método misto de apoio à decisão. Como resultado, duas listas de ordenação e priorização das alternativas foram determinadas, trazendo assim maior segurança e simplicidade ao processo decisório.
\end{abstract}

Palavra-chave: Auxílio multicritério à tomada de decisão; AHP TOPSIS 2N; poços de petróleo; furos de alívio de pressão.

Tópicos: Apoio Multicritério à Decisão, Gestão de Projetos, Gestão da Produção, PO na Área de Petróleo e Gás. 


\begin{abstract}
This paper aims to present a practical application of the tool AHP TOPSIS $2 \mathrm{~N}$, as a support for decision making in the oil industry and solution to the problem of ordering and prioritization of a list of twelve fluid injector wells to be intervened to perform relief holes (for reducing internal pressure of the linings). Fluid injector wells are used to maintain the internal pressure of the oil reservoir and thereby ensure greater recovery factor of oil and natural gas from the reservoir. Four criteria were selected by experts as being the most relevant for the construction of the decision matrix: production loss, well life to collapse, time to injection line change due to SCC CO2 phenomenon and type of fluid contained in the wells. annular spaces between well casings. With the data collected through simplified methodology, the AHP TOPSIS 2N program was executed, which is considered a mixed decision support method. As a result, two ordering and prioritization lists of alternatives were determined, thus bringing greater security and simplicity to the decision making process.
\end{abstract}

Keywords: Multicriteria decision making aid, AHP TOPSIS 2N, oil wells, pressure relief holes.

Topics: Multicriteria Decision Support, Project Management, Production Management, Oil \& Gas OR.

\title{
Como Citar:
}

BARBOSA, Humberto Magno; SANTOS, Marcos dos; GOMES, Carlos Francisco Simões. Aplicação do método híbrido AHP-TOPSIS-2N para a ordenação de execução de furos de alívio de revestimentos de poços de petróleo sob risco de colapso. In: SIMPÓSIO DE PESQUISA OPERACIONAL E LOGÍSTICA DA MARINHA, 19., 2019, Rio de Janeiro, RJ. Anais [...]. Rio de Janeiro: Centro de Análises de Sistemas Navais, 2019. 


\section{INTRODUÇÃO}

A indústria do petróleo no Brasil teve considerável crescimento nos últimos anos, do período de 2007 a 2016 ela saiu de patamares de 2,14 para 3,25 milhões de barris de óleo equivalente por dia (boe/d), que é soma da produção de petróleo e de gás natural em termos de óleo equivalente. Informações mais recentes, agosto de 2019, mostram que a produção brasileira de petróleo bateu novo recorde atingindo a marca de 3,8 mihões de boe/d, segundo a Agência Nacional do Petróleo, Gás Natural e Biocombustíveis (ANP).

As previsões para esta indústria são promissoras, a ANP estima que a produção de petróleo passará de 2,6, em 2018, para 7,5 milhões de barris por dia (bpd) em 2030, ou seja, um crescimento anual médio de 14,50\% em treze anos. Além disto, a exportação de petróleo passará de 1,2, em 2018, para 4 a 5 milhões de bpd, em 2030, representando um crescimento anual médio mínimo de 17,95\% no período. E para suportar este crescimento de volume da produção esperado, muitos equipamentos especializados desta indústria, tais como unidades estacionárias de produção (UEPs), têm sido demandados, e a expectativa é que essa demanda continue a crescer. Previsões da ANP mostram que a quantidade de UEPs instaladas e operando passarão de 106, em 2018, para aproximadamente 170 unidades, em 2030, representando um crescimento anual médio de 4,64\%. Além de todas as medidas que a ANP vem tomando junto com o Conselho Administrativo de Defesa Econômica (CADE) para desenvolver o mercado de gás natural no Brasil, que hoje ainda é concentrado, com medidas de abertura do mercado para novos agentes econômicos e ações como Programa Novo Mercado de Gás. O gás natural doméstico deve ganhar espaço na geração térmica, dando mais segurança ao sistema energético do país, e nos mercados industrial, comercial e residencial.

Com toda essa evolução do setor de óleo e gás natural vieram relevantes alterações na estrutura das indústrias do país, onde sua participação triplicou em valor da transformação industrial, de acordo com relatórios do Banco Nacional de Desenvolvimento Econômico e Social (BNDES), o que acarretou em aumento de empregos em diversas atividades correlacionadas nos últimos anos. No campo tributário, o governo estima uma mudança de patamar de pagamento de tributos por empresas petrolíferas, do tipo royalties e participações especiais, de 60, em 2018, para mais de 300 bilhões de reais em 2030, onde atingiria seu pico (ANP, 2019).

Não obstante a produção de petróleo e gás natural do país e geração de impostos, além disto, há a questão da energética, que sustenta a base de todas as atividades econômicas do país. A matriz energética brasileira, composta de cerca de $42,9 \%$ de energia renovável e considerada mais renovável que a matriz energética mundial, onde energias renováveis representam cerca de 14\%, possui grande dependência de petróleo. Do total de energia consumida no país, aproximadamente 49,4\% advém de petróleo, derivados e gás natural, de acordo com a Empresa de Pesquisa Energética (EPE).

Portanto, visto o exposto acima, percebe-se que, em termos estratégico, econômico, social e também energético, o setor de óleo e gás se posiciona como de extrema relevância para a soberania brasileira.

\subsection{Perfuração e Completação de poços de Petróleo}

A produção de petróleo ocorre por meio do fluxo do óleo e gás natural do reservatório à superfície. Nos casos de produção marítima, a produção passa pelos poços marítimos de produção e em seguida por linhas de produção (dutos rígidos e/ou flexíveis), que interligam poços à UEP. A produção, uma vez na plataforma, passa por um processamento primário, 
onde há a separação da mistura de óleo, gás natural e água no fluído, dando então seu devido tratamento particular para cada um deles, sendo o óleo armazenado para transporte, que pode ser por navios aliviadores ou por oleodutos, o gás, tratado para enquadramento de especificações técnicas de destinação a Unidades de Tratamento de Gás (UTG) e a água sendo tratada para possível reinjeção em reservatório ou até mesmo descarte no ambiente.

No Brasil, segundo relatórios da ANP, estima-se que mais de 86 mil poços produtores de petróleo e gás natural já foram perfurados entre as regiões de terra e mar. Desse total de poços, a região marítima representa cerca de $9,08 \%$. Os poços marítimos são os de maiores dificuldades de acesso, por conta das necessidades de transporte aéreo para equipamentos e pessoas, o que gera altos custos e demanda grande planejamento dos recursos, que em grande parte são críticos (de rara disponibilidade).

\subsubsection{Perfuração de Poços}

De acordo com Thomas, resumidamente, a perfuração de um poço de petróleo ocorre em duas fases: a de exploração e a de desenvolvimento. Atividades exploratórias objetivam a perfuração de poços para identificação de reservas de hidrocarbonetos, bem como dimensionar reservatórios e potenciais produtivos. Atividades de desenvolvimento ocorrem após descobertas de reservas de hidrocarbonetos, delineadas e confirmadas suas viabilidades comerciais, as chamadas declarações de comercialidade junto ao órgão regulador do país de atuação.

A perfuração rotativa é o método mais utilizado pela indústria do petróleo, mesmo que atualmente exista a combinação do rotativo e percussão. Nele uma torre de perfuração fica apoiada sobre uma superestrutura, onde localiza-se a chamada mesa rotativa. Esta mesa sustenta e comunica um torque à coluna de perfuração, que é composta por vários tubos conectados entre si e com uma broca cortante em sua extremidade inferior, conforme o avanço da broca perfura as formações geológicas sobrejacentes em direção aos potenciais reservatórios. A coluna de perfuração é aumentada a partir da superfície, à medida que a perfuração avança. A broca lança um fluido que circula pelo poço durante a perfuração, chamado de fluido de perfuração, este retorna à superfície através do espaço anular entre a coluna de perfuração e a parede do poço, arrastando a rocha triturada que é chamada de cascalho de perfuração. A figura 1 mostra um esquema de sonda de perfuração terrestre. 


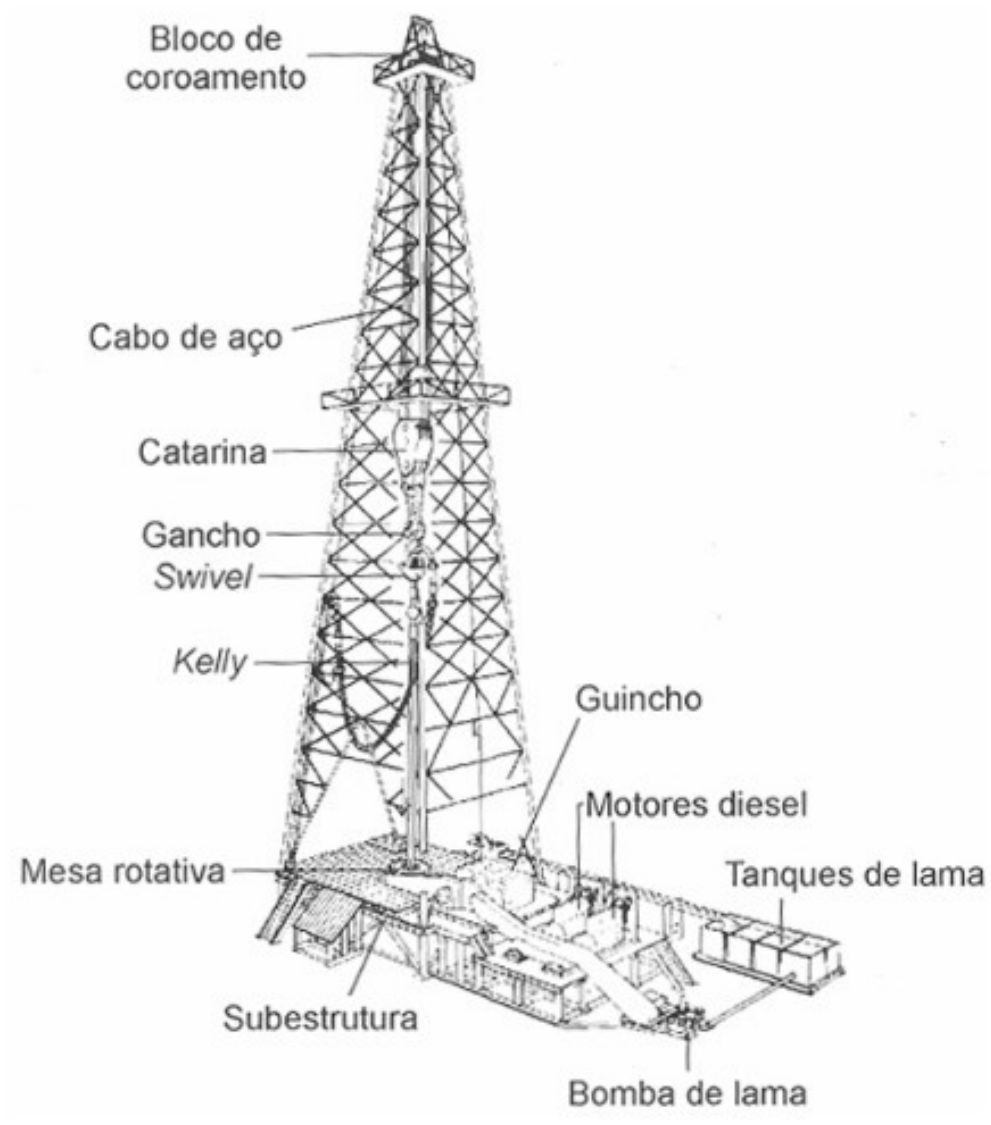

Figura 1 - Desenho esquemático de uma sonda rotativa terrestre, Fonte: Thomas, 2001.

\subsubsection{Completação de Poços}

Um poço, qualquer que seja o tipo dele, requer condições de operação de maneira segura e econômica em todo seu tempo de vida útil, e além disto, deve-se procurar otimizar sua vazão.

É chamado de completação o conjunto de operações destinados a equipar o poço para produzir óleo ou gás, ou até mesmo injetar diversos fluidos no reservatório. Esta completação deve tentar ser a mais permanente possível, minimizando assim a necessidade de intervenções e, portanto, paradas das atividades de produção.

Uma completação tradicional de um poço marítimo, com árvore de natal convencional e equipamentos de gas lift, segue as seguintes fases, em ordem cronológica: a) instalações dos equipamentos de superfície, b) condicionamento do poço e c) avaliação da qualidade de cimentação do poço.

a) Instalações de equipamentos de superfície: basicamente são instalados a cabeça de poço e o Blowout preventer (BOP), de maneira a conceder acesso ao interior do poço com a segurança requerida, permitindo a execução das fases seguintes.

b) Condicionamento do poço: nesta fase é feito o condicionamento do poço e a substituição do fluido de perfuração remanescente por um fluido de completação. No condicionamento é descido uma coluna com broca e raspador (figura 2), de modo a deixar o interior do revestimento de produção (e liner, quando existente) 
gabaritado e em condições de receber os equipamentos requeridos. A broca é utilizada para cortar os tampões de cimento e tampões mecânicos, que por ventura venham a existir no interior do poço, bem como os restos de cimentação. O raspador é uma ferramenta com lâminas retráteis, que desce raspando a parte interna do revestimento de produção, retirando o que foi deixado pela broca. Após o condicionamento do revestimento de produção, sua estanqueidade é testada sob pressão e feita as devidas correções, se houver vazamentos. CAENN, DARLEY e GRAY explicam que o fluido de completação, geralmente é uma solução salina, isenta de sólidos, compatível com a formação e com os fluidos nela contidos, de forma a não causar nenhum tipo de dano na formação, que restrinja a vazão do poço. Além disso, o fluido deve possuir peso específico capaz de fornecer pressão hidrostática no interior do poço um pouco superior à pressão estática da formação.

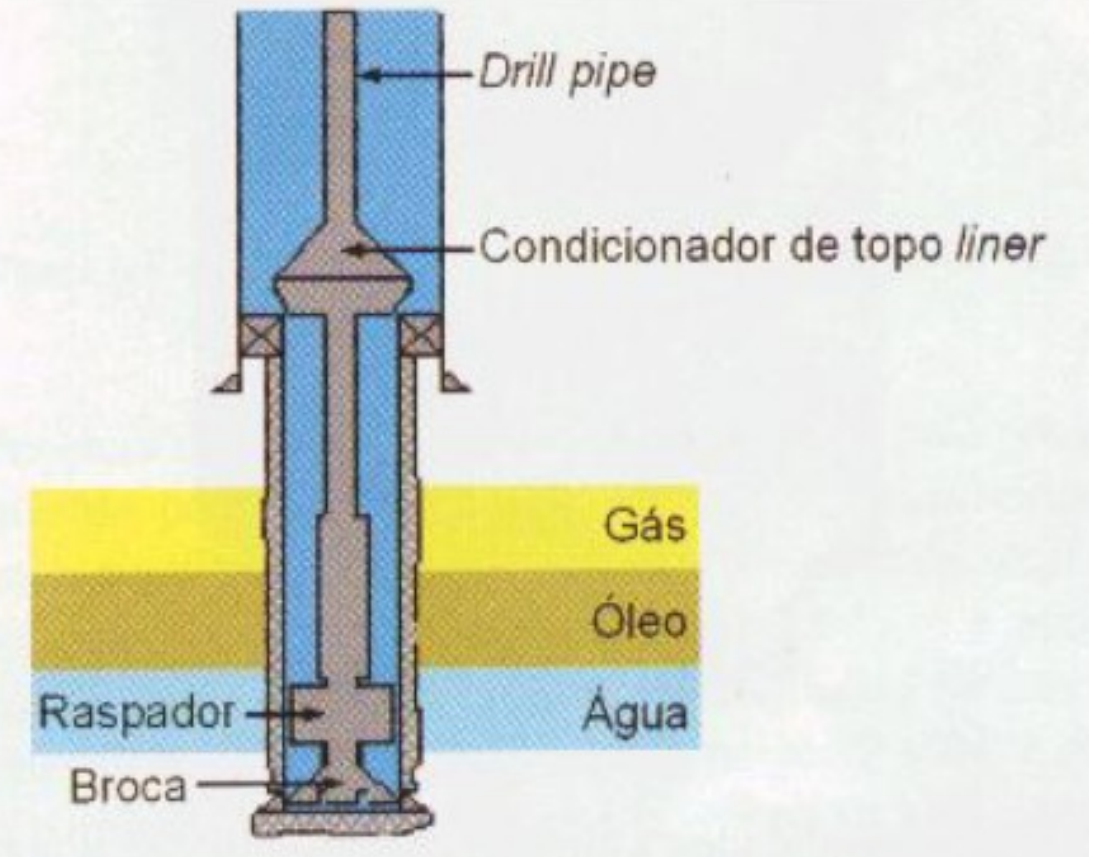

Figura 2 - Condicionamento do liner e substituição do fluido de perfuração por fluido de completação, Fonte: Thomas, 2001.

c) Qualidade da cimentação: A cimentação destina-se a promover vedação hidráulica entre os diversos intervalos permeáveis, ou até mesmo dentro de um único intervalo permeável, impedindo a intercomunicação de fluidos por detrás do revestimento, bem como propiciar suporte mecânico ao revestimento. A existência de uma efetiva vedação hidráulica é de fundamental importância técnica e econômica, garantindo um perfeito controle da origem (ou destinos) dos fluidos produzidos (ou injetados). O prosseguimento das operações no poço sem observação deste requisito pode gerar diversos problemas: produção de fluidos indesejáveis devido a proximidade dos contatos óleo/água ou gás/óleo, teste de avaliação das formações incorretos, prejuízo no controle dos reservatórios e operações de estimulação mal sucedidas, com possibilidades inclusive de perda do poço. Para se inferir a existência ou não de intercomunicações entre os intervalos de interesse, avalia-se a qualidade da cimentação, que é função de uma série de fatores tais como geometria do poço, qualidade do cimento, parâmetros de injeção e centralização do revestimento centralização. Caso seja comprovada a não existência de vedação hidráulica se 
procede a correção da cimentação primária, efetuando canhoneio (furos no revestimento) e a compressão do cimento nos intervalos deficientes. A decisão quanto a necessidade ou não da correção de cimentação é uma tarefa de grande importância e deve ser tomada com máxima de segurança possível, pois a operação, principalmente no caso de poços marítimos. Para se avaliar a qualidade da cimentação são utilizados perfis acústicos, que medem a aderência do cimento ao revestimento e do cimento à formação. Em função da interpretação dos perfis obtidos se decide quanto a necessidade ou não de correção da cimentação.

\subsubsection{Integridade de Poço e Furo de Alívio de Pressão}

É prática comum da indústria de óleo e gás a identificação de possíveis riscos e consequências associadas a cenários perigosos, bem como a existência de meios de detecção e salvaguardas. Esta identificação é elaborada por meio de processo de Análise de Riscos.

\subsubsection{Integridade de Poços, risco de colapso e impactos ambientais}

Durante a Análise de Riscos dos Poços, foi identificado o risco de poço ser submetido a esforços de colapso maiores do que o limite de resistência dos materiais de revestimentos de poço, durante a injeção de fluido no poço a baixas temperaturas em estado transiente, tendo em vista que a pressão confinada internamente ao revestimento se reduz pelo resfriamento mais rápido do que a externa, aumentando o esforço de colapso deste revestimento, podendo haver comprometimento total do poço. A figura 3 ilustra um esquema de revestimento de poço.

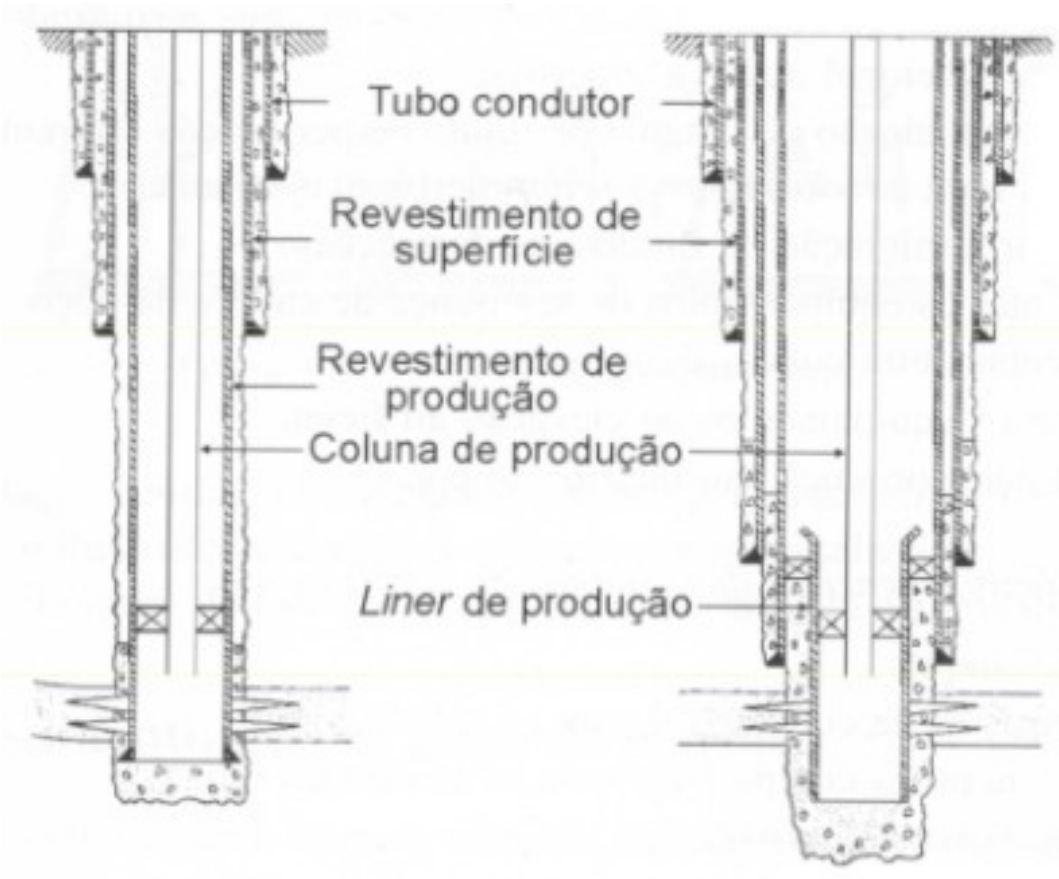

Figura 3 - Esquema de revestimento de poço.

Fonte: Thomas, 2001.

Em caso de comprometimento e colapso de poço, a produção deve ser parada para intervenção, acarretando assim prejuízo financeiro. 


\subsubsection{Furo de Alívio de Pressão Como Solução}

Para resolução deste possível problema, a Análise de Riscos recomendou a realização de furo de alívio nos revestimentos condutores de superfície e intermediário permitindo a equalização de pressões entre os revestimentos. Além disto, para o caso do fluido de completação baseado em óleo, foi recomendado também o recolhimento deste líquido a fim de mitigar possíveis impactos ambientais, porém isto requer ferramenta especializada para recolhimento do material.

\section{FUNDAMENTAÇÃO TEÓRICA}

Abordagens baseadas em métodos de tomada de decisão com múltiplos critérios, composto por técnicas de TDMA, geralmente são adotadas para auxiliar em problemas complexos de seleção com fatores qualitativos e quantitativos, caracterizados por objetivos múltiplos e conflitantes, normalmente difíceis medir.

\subsection{PROblema de tomada de decisão com múltiplos CRITÉRIOS}

O problema de tomada de decisão com múltiplos atributos (TDMA) é o processo de tomada de decisão sobre várias alternativas na presença de vários critérios. Nos problemas do TDMA, escolher a melhor alternativa entre várias alternativas é o principal objetivo.

\subsection{MULTIPLOS CRITÉRIOS PARA TOMADA DE DECISÃO}

De acordo com Saaty e Ergu, uma decisão deve estar munida de: alta compreensão do problema escolhido, assim, espera-se que dúvidas e incertezas estejam minimizadas; estrutura que represente os fatores envolvidos nos critérios e alternativas; escala que se possa representar julgamentos; prioridades calculadas através de julgamentos numéricos.

Gomes et al relatam também que em uma tomada de decisão de qualidade outros aspectos devem estar envolvidos: (1) uma compreensão do decisor em termos da necessidade e ponderação da decisão considerando variáveis de diversas áreas de conhecimento, tais como no campo tecnológico, financeiro, logístico, operacional e etc; (2) emprego de metodologia ou combinação de metodologias que permitam a identificação das variáveis e uma avaliação lógica das informações; e (3) reflexão sobre necessidade e viabilidade de difusão do processo de tomada de decisão para garantir o apoio necessário na implementação da alternativa escolhida. Os métodos MCDM e MCDA são aplicados quando há necessidade de selecionar, classificar, classificar ou descrever as alternativas atuais em um processo complexo de tomada de decisão com vários critérios e objetivos conflitantes.

\subsection{MÉTODOS DE TOMADA DE DECISÃO}

Para o propósito de solução de problema de tomada de decisão, a literatura versa sobre a existência de vários métodos, e Abootalebi, Hadi-Vencheh e Jamshidi relatam que alguns dos métodos clássicos são: VlseKriterijumska Optimizacija I Kompromisno Resenje; Analytic Hierarchy Process, Simple Additive Weighting Elimination Et Choice Translating Reality, Preference Ranking Organization METHods for Enrichment Evaluations e Technique for Order Preferences by Similarity to an Ideal Solution (TOPSIS). 
Sendo o método TOPSIS bem famoso dentre os demais listados acima, e reconhecido como de fácil uso, visto que diversos pesquisadores escolhem empregar esse método para solucionar problemas de TDMA.

Wanke descreve o método TOPSIS como sendo definido em seis etapas: 1) normalizar a matriz de decisão, 2) calcular a matriz de decisão normalizada ponderada, 3) determinar a solução ideal positiva (PIS) e a solução ideal negativa (NIS), 4) calcular as separações de uma alternativa do PIS e do NIS, 5) calculam a proximidade relativa de uma alternativa ao PIS e 6) organizam a proximidade relativa em uma ordem decrescente para obter a melhor alternativa.

Para Zavadskas et al., embora com muitos usos e vantagens, o método TOPSIS também possui algumas desvantagens. Uma dessas questões se diz respeito ao método de normalização. Quando o método de normalização muda, o ranking também muda.

\section{METODOLOGIA}

A metodologia utilizada para este trabalho se caracteriza pelas seguintes etapas: 1) definição dos critérios relevantes por decisores de projetos e especialistas do assunto; 2) coleta dos dados para modelagem do problema; 3) execução dos cálculos de ordenação e priorização através do software AHP TOPSIS 2N;4) análise dos resultados calculados. A figura abaixo esclarece o processo de metodologia.

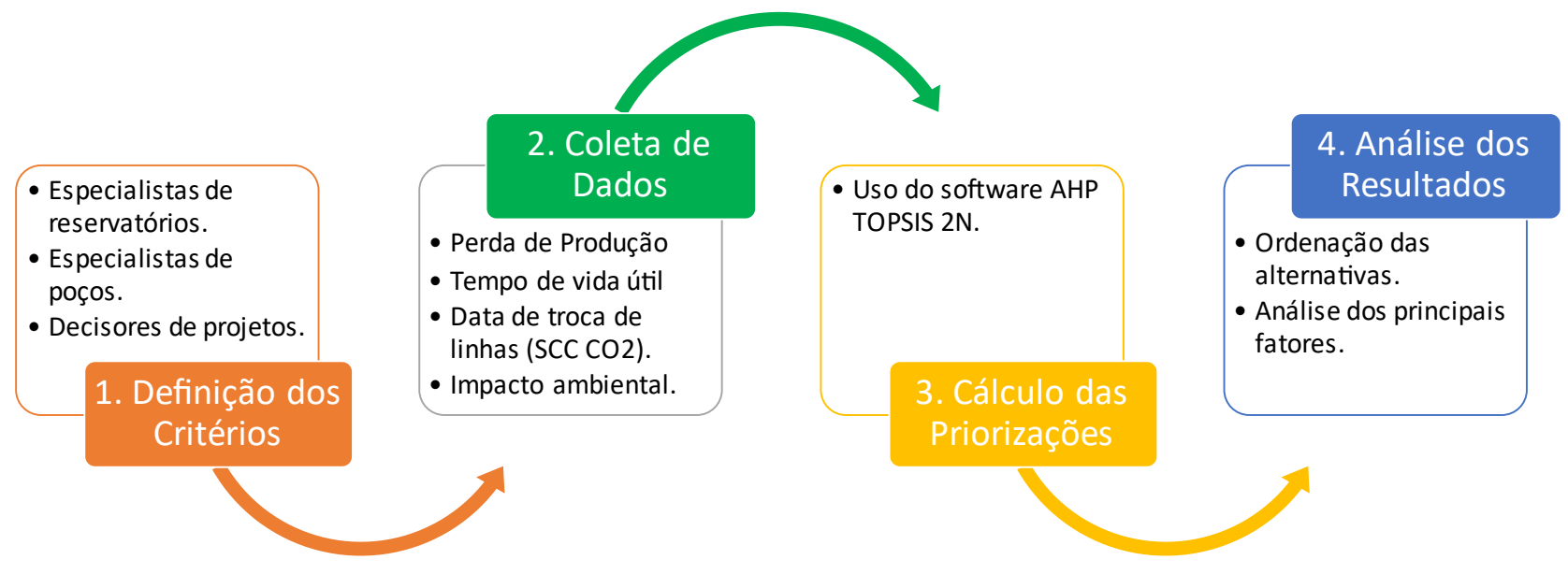

Figura 4: Metodologia

Fonte: Autores

\subsection{DEFINIÇÃO DOS CRITÉRIOS}

Foi realizada uma reunião entre quatro decisores dos projetos onde os doze poços fazem parte do escopo, juntamente com mais dois especialistas nos assuntos de reservatórios e de poços, e chegou-se à conclusão que os fatores mais importantes a serem considerados para o problema são quatro, descritos logo a segui:

a) Estimativas para capacidade de produção de petróleo e gás natural para cada plataforma nas condições de execução do procedimento de "rampagem” e também na situação em condições normais;

Esse critério visa estimar a perda da produção de petróleo e, consequentemente, receita monetária por uma diferença entre o que se produzirá em condição de rampagem e o potencial de produção em condições normais. 
b) Tempo de vida útil de cada poço operando em situação de pressão; Esse critério visa indicar o prazo que cada poço pode continuar operando e quanto tempo a companhia tem para encontrar a solução e a implementá-la com êxito, antes que se tenha algum tipo de prejuízo.

c) Data da necessidade de intervenção dos poços para realização de troca de linhas de produção devido ao fenômeno de corrosão por causa de SCC $\mathrm{CO}_{2}$;

d) Identificação dos poços que possuem fluídos de perfuração do tipo baseado em água e do tipo baseado em óleo.

\subsection{COLETA DOS DADOS RELEVANTES PARA O PROBLEMA}

Os dados do problema em questão foram obtidos junto a uma companhia petrolífera. Foi solicitado as áreas funcionais da companhia, especializadas nos assuntos de reservatório e de poço, que elas fornecessem as informações dos critérios descritos na seção 3.1, definição dos critérios.

Na sequência da definição dos critérios, eles foram comparados par-a-par pelos decisores, que, através de consenso, deram as notas, observando a escala fundamental de Saaty. Com este procedimento, foi obtido a matriz importância com os pesos de cada critério, descrita no quadro abaixo. Esta matriz de importância possui índice de consistência 0,0724, ou seja, menor que 0,10 , conforme recomendado pela literatura.

Quadro 1 - Matriz Importância dos Critérios

\begin{tabular}{|c|c|c|c|c|}
\cline { 2 - 4 } \multicolumn{1}{c|}{} & $\begin{array}{c}\text { Perda de } \\
\text { produção }\end{array}$ & $\begin{array}{c}\text { Tempo de } \\
\text { vida útil } \\
\text { do poço } \\
\text { em } \\
\text { situação } \\
\text { de risco }\end{array}$ & $\begin{array}{c}\text { Dias até a } \\
\text { troca da linha } \\
\text { de produção } \\
\text { por fenômeno } \\
\text { de SCC cO2 }\end{array}$ & $\begin{array}{c}\text { Impacto } \\
\text { ambiental do } \\
\text { fluido de } \\
\text { completação }\end{array}$ \\
\hline $\begin{array}{c}\text { Perda de produção } \\
\text { Pempo de vida útil do poço em situação } \\
\text { de risco }\end{array}$ & 0,33 & 3 & 5 & 9 \\
\hline $\begin{array}{c}\text { Dias até a troca da linha de produção } \\
\text { por fenômeno de SCC CO2 }\end{array}$ & 0,20 & 0,33 & 3 & 5 \\
\hline $\begin{array}{c}\text { Impacto ambiental do fluido de } \\
\text { completação }\end{array}$ & 0,11 & 0,20 & 0,14 & 1 \\
\hline
\end{tabular}

Fonte: Autores

Como resultado da matriz importância, os critérios tiveram suas relevâncias calculadas e são apresentadas abaixo.

- $\quad$ Perda de produção = 57,12\%;

- Tempo de vida útil do poço = 25,06\%;

- Tempo até a troca da linha de produção = $13,85 \%$;

- Impacto ambiental gerado pelo tipo de fluido de completação do poço $=3,98 \%$.

\section{APLICAÇÃO DO MÉTODO AHP TOPSIS 2N}

O programa AHP TOPSIS 2N, desenvolvido por meio de uma parceria entre o Instituto 
Militar de Engenharia (IME), o Centro de Análises de Sistemas Navais (CASNAV) e a Universidade Federal Fluminense (UFF), foi utilizado de forma a automatizar as contas do método.

\subsection{MATRIZ DECISÃo}

O Quadro 2 apresentada a matriz decisão para o caso. Os dados originais tiveram que ser caracterizados devido a confidencialidade do assunto.

Quadro 2 - Matriz Decisão

\begin{tabular}{|c|c|c|c|c|}
\hline Alternativas & Perda de Produção & $\begin{array}{c}\text { Tempo de vida útil } \\
\text { do poço em situação } \\
\text { de risco }\end{array}$ & $\begin{array}{c}\text { Dias até a troca da linha } \\
\text { de produção por } \\
\text { fenômeno de SCC CO2 }\end{array}$ & $\begin{array}{c}\text { Impacto ambiental do } \\
\text { fluido de } \\
\text { completação }\end{array}$ \\
\hline A & 16 & 0 & 1 & 1 \\
\hline B & 16 & 740 & 852 & 10 \\
\hline C & 16 & 511 & 1.500 & 10 \\
\hline D & 16 & 210 & 1 & 10 \\
\hline E & 1 & 365 & 1.121 & 10 \\
\hline F & 1 & 229 & 898 & 10 \\
\hline G & 161 & 124 & 1 & 10 \\
\hline H & 161 & 463 & 1.251 & 10 \\
\hline I & 161 & 740 & 1.288 & 10 \\
\hline J & 190 & 146 & 831 & 10 \\
\hline K & 190 & 146 & 566 & 10 \\
\hline L & 190 & Fon & & 10 \\
\hline
\end{tabular}

Fonte: Autores

\subsection{PARAMETRIZaÇão do PROGRAMA AHP-TOPSIS-2N}

A partir da matriz de decisão, contendo as doze alternativas de poços e suas notas nos quatro critérios, o programa foi alimentado, seguindo todas suas etapas:

a) Determinação do quantitativo de critérios;

b) Alimentação dos valores dos pesos das importâncias para cada um dos critérios;

c) Definição das alternativas;

d) Alimentação dos valores de cada alternativa para cada critério

e) Definição do sentido da otimização da solução ideal para cada critério.

f) E, por fim, execução do programa.

\subsection{RESUltados}

Como resultado final, duas listas de ordenação e priorização das alternativas foram geradas, elas são relativas aos dois tipos de normalização que o método utiliza. As listas obtiveram resultados iguais entre si e podem ser vistos no Quadro 3. 
- Ordenação da normalização 1

Quadro 3 - Priorização da Normalização 1

\begin{tabular}{|c|c|c|}
\hline $\begin{array}{c}\text { Alternati- } \\
\text { va }\end{array}$ & $\begin{array}{c}\text { Ordena- } \\
\text { ção }\end{array}$ & $\begin{array}{c}\text { Pontuação de Desempe- } \\
\text { nho }\end{array}$ \\
\hline K & 1 & 0,9135 \\
\hline J & 2 & 0,9116 \\
\hline G & 3 & 0,8452 \\
\hline L & 4 & 0,7186 \\
\hline H & 5 & 0,709 \\
\hline I & 6 & 0,5947 \\
\hline A & 7 & 0,3467 \\
\hline D & 8 & 0,3284 \\
\hline F & 9 & 0,286 \\
\hline C & 10 & 0,1991 \\
\hline E & 11 & 0,1931 \\
\hline B & 12 & 0,1459 \\
\hline
\end{tabular}

Fonte: Autores

- Ordenação da normalização 2

Quadro 4 - Priorização da Normalização 2

\begin{tabular}{|c|c|c|}
\hline $\begin{array}{c}\text { Alternati- } \\
\text { va }\end{array}$ & $\begin{array}{c}\text { Ordena- } \\
\text { ção }\end{array}$ & $\begin{array}{c}\text { Pontuação de Desempe- } \\
\text { nho }\end{array}$ \\
\hline K & 1 & 0,9211 \\
\hline J & 2 & 0,9192 \\
\hline G & 3 & 0,8454 \\
\hline L & 4 & 0,7426 \\
\hline H & 5 & 0,7273 \\
\hline I & 6 & 0,6184 \\
\hline A & 7 & 0,3184 \\
\hline D & 8 & 0,3068 \\
\hline F & 9 & 0,2626 \\
\hline C & 10 & 0,1847 \\
\hline E & 11 & 0,1745 \\
\hline B & 12 & 0,1374 \\
\hline
\end{tabular}

Fonte: Autores

\section{ANÁLISES DOS RESULTADOS}

De posse dos resultados, percebe-se que as posições dos primeiros colocados, as alternativas K e J, têm como fatores impulsionadores do seu desempenho o critério perda de produção (ambas com 190 pontos) e troca de linha de injeção por fenômeno de SCC $\mathrm{CO}_{2}$, que também são uns dos mais altos (1.288 e 1.251). A terceira posição aparece para a alternativa 
G, que, embora tenha menor pontuação no critério produção (161 pontos) quando comparada com a quarta colocada, alternativa L, é compensada pelo critério tempo de vida útil do poço operando em condições de pressão (124 pontos) e também dias até troca da linha de injeção (1.287 pontos), ou seja, a influência do segundo e terceiro critérios mais relevantes invertem o resultado do critério mais influente. Na sequência, tem-se as alternativas $H$, priorizada em função dos seus altos valores de perda de produção e tempo para troca de linha (161 e 898 pontos respectivamente), bem como a alternativa I. A alternativa A, posicionada em sétima colocação, é impulsionada pelo baixo tempo de vida útil do poço (1 ponto) e pela baixa pontuação em dias até a troca da linha de produção (1 ponto). Alternativas D e F alcançam a oitava e nona posições respectivamente devido ao alto tempo de troca de linha de injeção (1.500 e 1.121 pontos) e médio prazo de tempo de vida útil dos poços (210 e 229 pontos). A décima colocada, alternativa $\mathrm{C}$, caracteriza-se como aquela de valores médios nos variados resultados, ou seja, de maior balanceamento entre os critérios. E, por fim, alternativas E e B enquadram-se como as últimas colocadas, tendo como característica forte o critério de impacto ambiental do fluido contido no poço, porém este possui baixa expressividade perante aos três outros critérios.

\section{CONCLUSÃO}

Visto a quantidade de elementos empregados no problema, percebe-se que a consideração de diversos critérios e muitas alternativas faz o caso estudado se configurar como de alta complexidade para gestão. Porém, o método, aliado ao programa AHP TOPSIS $2 \mathrm{~N}$, que traz uma automatização dos cálculos, faz com que a avaliação do problema seja bem mais simplificada, contando com maior segurança na escolha realizada.

A utilidade de uma ferramenta como esta é grande, pois suporte gerencial para problemas de altas proporções como o caso apresentado, seja nos aspectos financeiros, traduzido pela perda de produção, seja no tempo disponível para realização de um trabalho, evitando-se um risco iminente de colapso, e até mesmo empregando critérios de preservação ambiental como fatores decisivos, faz com que muita economia, eficiência e eficácia seja conseguida em uma companhia inserida em um ambiente competitivo e altamente regulado por órgãos governamentais fiscalizadores das atividades do setor. Além disto, dificuldades de obtenção dos equipamentos para execução dos trabalhos requeridos de intervenção em poços, por se tratar muitas das vezes de ferramentas raras e, portanto, de baixa disponibilidade para seu uso, requerem uma programação que otimize tais recursos.

Desta maneira, fica evidente a contribuição do emprego do método nos ambientes corporativos, que criam e ofertam produtos, em muitos casos, essenciais as atividades da sociedade e que por isto perseguem aumento de capacidade, segurança e qualidade através de práticas gerenciais cada vez melhores.

\section{REFERÊNCIAS BIBLIOGRÁFICAS}

[1] Boletim Mensal da Produção de Petróleo e Gás Natural. Agência Nacional do Petróleo, Gás Natural e Biocombustíveis (ANP), 2019. Disponível em: http://www.anp.gov.br/arquivos/publicacoes/boletins-anp/producao/2019-08boletim.pdf. Acesso em: 25 out. 2019.

[2] $7^{\circ}$ Fórum LIDE 2019, 14/06/2019 - A Indústria de Petróleo e Gás no Brasil - Principais Temas. Agência Nacional do Petróleo, Gás Natural e Biocombustíveis (ANP), 2019. 
Disponível em: $\quad$ http://www.anp.gov.br/arquivos/palestras/2019.06.14 DecioOddone.pdf. Acesso em: 23 out. 2019.

[3] Panorama setorial 2015 a 2018 Petróleo e Gás. Banco Nacional de Desenvolvimento Social (BNDES). Disponível em:

https://web.bndes.gov.br/bib/jspui/bitstream/1408/14641/1/ Petróleo e gás_P_BD.pdf. Acesso em: 15 out. 2019.

[4] Matriz energética e elétrica brasileira. Empresa de Pesquisa Energética (EPE). Disponível em: http://www.epe.gov.br/pt/abcdenergia/matriz-energetica-e-eletrica. Acesso em: 25 out. 2019.

[5] THOMAS, J.E., Fundamentos de Engenharia de Petróleo, editora Interciência, $2^{\circ}$ edição, Rio de janeiro, 2001, 271p.

[6] CAENN, R.; DARLEY, H. C. H.; GRAY, G. R. - Fluidos de Perfuração e Completação - Composição e Propriedades ; Tradução da $6^{a}$ edição; Editora Elsevier; Rio de Janeiro, 2014.

[7] SAATY T. L; e ERGU D. When is a decision-making method trustworthy? Criteria for evaluating multi-criteria decision-making methods. International Journal of Information Technology \& Decision Making 14(6), pp.1171-1187, 2015.

[8] WANKE, P.; AZAD, A. K.; e BARROS, C. P. Predicting efficiency in Malaysian Islamic banks: A two-stage TOPSIS and neural networks approach. Res.Int. Bus. Finance. vol. 36, pp. 485-498, 2016.

[9] ABOOTALEBI, S; HADI-VENCHEH A.; e JAMSHIDI, A. Ranking the Alternatives With a Modified TOPSIS Method in Multiple Attribute Decision Making Problems. IEEE transactions on engineering management.

[10] ZAVADSKAS, E. K.; ZAKAREVICIUS, A.; e, ANTUCHEVICIENE J., Evaluation of ranking accuracy in multi-criteria decisions. Informatica, vol. 17, no. 4, pp. 601-618, 2006.

[11] GOMES C. F. S.; COSTA, H. G.; e BARROS A. P. Sensibility analysis of MCDA using prospective in Brazilian energy sector. Journal of Modelling in Management 12(3) (2017) 475-497

[12] RIBEIRO, Wallace Lima; SANTOS, Marcos dos; GOMES, Carlos Francisco Simões. AHP-TOPSIS-2N Software (v.1). Desenvolvido por meio de uma parceria entre o Institulo Militar de Engenharia (IME), o Centro de Análises de Sistemas Navais (CASNAV) e a Universidade Federal Fluminense (UFF). 